\title{
Cell-Cell Interactions during the Migration of an Identified Commissural Growth Cone in the Embryonic Grasshopper
}

\author{
Paul Z. Myers and Michael J. Bastiani \\ Department of Biology, University of Utah, Salt Lake City, Utah 84112
}

One of the fascicles of the posterior commissure of the embryonic grasshopper is pioneered by an individually identifiable neuron named $Q 1$. Q1 initially grows along a longitudinal pathway established by another pioneer neuron, MP1, and then crosses to the midline, where it meets and fasciculates with the axon of the contralateral Q1. The Q1 growth cone follows the contralateral $Q 1$ axon to the contralateral longitudinal pathway, where it then fasciculates with axons of the MP1/dMP2 fascicle. In this work, we have identified a small set of early neurons that $Q 1$ could use as guidance cues while negotiating its way along a specific and stereotyped pathway to the midline. Furthermore, we have observed characteristic morphological changes in the Q1 growth cone that could indicate responses to changing adhesivity in the substrates it contacts. We have also quantified the pattern of dye coupling between neurons in this system. Most of the neurons to which $Q 1$ becomes coupled retain a strong, consistent pattern of dye coupling that shows no recognizable variation at times when growth cones are making pathway decisions. However, we have found one clear instance of transient, site-specific dye coupling between the Q1 growth cone and the ipsilateral MP1 soma.

The timing and pattern of dye coupling in this system suggest that dye coupling may play a role in synchronizing the initiation of axon outgrowth among a small population of neurons. Although dye coupling may not play a direct role in neuronal pathfinding, it may exert a profound indirect influence on neuronal interactions by regulating the timing of axon outgrowth.

[Key words: growth cone, dye-coupling, commissure, grasshopper, pathfinding, filopodia, confocal microscopy]

Current thinking about the mechanisms that guide axon outgrowth is dominated by the idea that growth cones are led to their targets by a series of local interactions. Growth cones may contact particular guidepost cells and use them as navigational cues (Bentley and Keshishian, 1982; Taghert et al., 1982; Bentley and Caudy, 1983a), or follow specific adhesive substrates (Bentley and Caudy, 1983b; Bastiani et al., 1984; Blair and Palka, 1989) or regional disparities (Letourneau, 1975; Hammarback et al., 1985; Burmeister and Goldberg, 1988). The local interactions often can be thought of as simple mechanical or physical

Received Oct. 25, 1991; revised Jul. 13, 1992; accepted Jul. 15, 1992.

We thank Rommy von Bernhardi, Ellen Carpenter, Rolf Karlstrom, and Elaine Seaver for their discussion and helpful criticism of the manuscript. This work was supported by 5T32 CA09602 and NS08656 to P.Z.M. and NS25378 and a McKnight Foundation award to M.J.B.

Correspondence should be addressed to Dr. Paul Z. Myers at the above address. Copyright (c) 1993 Society for Neuroscience $0270-6474 / 93 / 130115-12 \$ 05.00 / 0$ interactions, such as haptotaxis or passive steering to regions of increased adhesivity (Letourneau, 1982), but there are a number of reports of discrete, dynamic reactions to specific contacts, such as growth cone inhibition (Kapfhammer and Raper, 1987; Cox et al., 1990; Raper and Kapfhammer, 1990) or rapid changes in intracellular ionic concentrations (Kater et al., 1988) that can generate novel growth cone behaviors.

There are also reports in the literature that describe important interactions at a distance. For instance, diffusable growth factors affect the outgrowth of peripheral sensory fibers (Levi-Montalcini and Angeletti, 1968; Gundersen and Barret, 1979) and neurons of the CNS (Thoenen et al., 1987). The axons of commissural neurons can be induced to extend toward isolated portions of the floorplate by diffusible tropic factors (Tessier-Lavigne et al., 1988). Commissural neurons represent a particularly interesting problem in growth cone navigation, because it is difficult to explain their behavior in terms of exclusively local adhesive interactions. Commissural growth cones must reject the closest, ipsilateral target and grow across the midline to select a more remote, but presumably equivalent, contralateral target. Possible mechanisms for this initial disregard of the ipsilateral target include physical constraints on turning by growth cones (Katz, 1985; Lefcourt and Bentley, 1989), simple unavailability due to timing differences, timing-dependent variations in preferences driven by intrinsic factors such as maturation, or location-dependent respecification of a growth cone's targets by informative interactions en route (Bovolenta and Dodd, 1990).

One approach to identifying potentially important interactions for pathfinding is to observe the changing behavior of growth cones and thereby deduce the identity of environmental cues recognized by the cell. Growth cones have been observed to make characteristic changes in their rate of growth (Raper et al., 1983; Myers et al., 1986) or size and shape (Tosney and Landmesser, 1985; Bovolenta and Mason, 1987) when they reach specific choice points. Sites of preferential adhesion also can be implied by a nonrandom, stereotyped disposition of filopodia (Taghert et al., 1982; Bastiani et al., 1984; Bray and Chapman, 1985).

The presence of important cell-cell interactions also may be revealed by the appearance of temporally and spatially specific pattcrns of dyc coupling, mcdiatcd by gap junctions. Very early in embryonic development, all cells tend to be coupled together by gap junctions; the systematic loss of junctional communication between embryonic tissues during histogenesis may play a role in restricting a cell's fate, and the retention of coupling within a tissue may help maintain a common program of development for those cells (Guthrie et al., 1988; Guthrie and Gilula, 1989). The embryonic nervous system is a unique tissue in that its cells become uncoupled from one another early in 
their differentiation (Caveney, 1985), but then secondarily recouple to other neurons during the course of their outgrowth (Lo Presti et al., 1974; Bentley and Keshishian, 1982; Raper and Goodman, 1982; Eisen et al., 1989). Like their counterparts in other tissues, gap junctions in the developing nervous system could play a role in determination, maintenance, or differentiation of tissue-specific properties (Caveney, 1985); their correlation with contacts with guidepost neurons (Bentley and Keshishian, 1982) and with changes in growth cone motility (Kater et al., 1988) suggests that gap-junctional communication may also play a role in pathfinding. However, dye coupling is a widespread phenomenon, and gives little evidence of specificity; attempts to disrupt the pattern of gap-junctional communication by ablating individual elements in the network have shown no effect on pathfinding (Eisen et al., 1989); and not all growing neurons dye couple to other cells along their path of outgrowth (Holt, 1989). In principle, the formation of gap junctions that allow small cytoplasmic factors to travel freely between cells should be a significant opportunity for cell-cell communication, but the relcvance of this communication during neurogenesis is not well understood.

In this work, we characterize in detail a particularly simple system of neurons that has substantial advantages for dissecting the various interactions involved in guiding a commissural neuron to its target. The commissural neuron Q1 of the embryonic grasshopper highlights the complications of commissural outgrowth, yet is part of a very small subset of mutually interacting neurons that are amenable to experimental manipulation. When Q1 begins axogenesis, its emerging growth cone almost immediately contacts the descending axons of the MP1/dMP2 fascicle and grows along the fascicle for a short distance. Q1 quickly abandons the ipsilateral MP1/dMP2 fascicle, however, to grow across the midline and fasciculate instead with the contralateral MP1/dMP2 fascicle. Q1's outgrowth begins very early in the development of the nervous system, at a time when only a few ncurons have begun axogenesis. Q1 contacts only a handful of neurons during the time that it makes essential guidance decisions.

The neurons with which Q1 interacts have all been previously described (Raper and Goodman, 1981; Taghert et al., 1982). In this article, we present a comprehensive time series of Q1's outgrowth produced with confocal microscopy. We have distinguished a number of reproducible morphological events that are suggestive of specific, testable growth cone interactions with putative guidepost cells that lie along Q1's path of outgrowth. In addition, we have made quantitative measures of dye coupling to reveal potential intercellular signaling events that may play a role in respecifying Q1's target choice.

\section{Materials and Methods}

Lucifer yellow injections. We obtained grasshopper embryos, Schistocerca americana, from a colony maintained at the University of Utah. We dissected embryos from their eggs in a dish of culture medium and staged them according to the criteria of Bentley et al. (1979). The medium consisted of $1.33 \%$ glycine dissolved in a solution of $55.6 \%$ Schneider's Drosophila medium (GIBCO) and $44.4 \%$ minimum essential medium (MEM) (GIBCO), with $0.001 \mu \mathrm{g} / \mathrm{ml}$ of juvenile hormone (Sigma) and $0.001 \mu \mathrm{g} / \mathrm{ml}$ of $\beta$-ecdysterone added. We then pinned embryos dorsal side up on a slide in a drop of medium placed on a Zeiss standard microscope, and observed them with a Leitz $50 \times$ water immersion lens and Nomarski optics. Individual neurons were impaled with glass microelectrodes drawn on a Sutter model P-80 puller and filled with $0.5 \%$ Lucifer yellow in Ringer's solution. Dye was iontophoresed into the cells using a minimal amount of constant hyperpolarizing current, typically less than $0.5 \mathrm{nA}$, which was maintained for 5 to $15 \mathrm{~min}$.
Dye coupling. We injected the cells Q1, MP1, and posterior corner cell ( $\mathrm{pCC})(\mathrm{n}=249)$ with dye at $30-35 \%$ of development, and measured the time required for the dye to pass from the injected neuron to other cells. To minimize photodamage, we observed cells only briefly once every $15 \mathrm{sec}$ for the first minute after the injection, once every $30 \mathrm{sec}$ for the next $2 \mathrm{~min}$, and once every $60 \mathrm{sec}$ thereafter. Under this regimen, the cells remained apparently healthy (i.e., there was no blebbing or deterioration of fine processes) for up to $15 \mathrm{~min}$.

Injections were not analyzed if they failed to meet two criteria: (1) the injected cell had to be sufficiently differentiated that it had uncoupled from most of its neighbors, and (2) the injected cell had to exhibit coupling to at least one other specific cell. Eight percent of the injections were rejected because they failed to meet the first criterion. All of these cases occurred early, at $31 \%$ of embryogenesis or earlier, and produced a widespread diffusion of dye that we interpret to indicate that the injection was made prior to the normal uncoupling and differentiation of the cell. Another $13 \%$ failed to meet the second criterion. Each of the three cell types has an adjacent neuron to which it is strongly coupled: $\mathrm{Q} 1$ is paired with $\mathrm{Q} 2, \mathrm{pCC}$ with an anterior corner cell (aCC), and MP1 with two neurons, dMP2 and VMP2. If dye failed to pass from the injected cell to its neighbor, we assumed that the injection procedure had traumatized the cell and forced an artificial uncoupling.

Of the successful injections, we measured the latency, or time required for an observable quantity of dye to pass from the injected cell to any other cells to which it was dye coupled. One serious difficulty with any study of dye coupling is that the phenomenon is extremely fragile and variable; the process of penetrating the membrane to introduce the dye can be sufficiently traumatic to trigger partial or complete uncoupling. We cannot eliminate all experimental artifacts from this kind of study, but we offer two observations that validate our measurements. First, all the cells studied couple strongly to an adjacent and usually related cell, providing an internal control. Second, some of our numbers speak for the consistency and delicacy of our technique (Table 1). We observed pairs of cells (e.g., Q1 to the corner cells, or the corner cells to MP1) that were dye coupled virtually $100 \%$ of the time in our experiments, suggesting that our technique must not cause severe, long-term damage to the cells.

There is, however, substantial variation in the latency of dye transfer between any pair of cells. The time required for dye to transfer from Q1 to the corner cells, for example, required between 15 and $300 \mathrm{sec}$. We did not miss any instances of dye coupling because we failed to wait sufficiently for the dye to transfer. We observed the injections for at least $5 \mathrm{~min}$ beyond the time the last new, directly coupled cell was observed to take up the dye. This represents enough time to start seeing obvious instances of indirect coupling; for example, Lucifer yellow might pass from MP1 to dMP2 and VMP2 within $30 \mathrm{sec}$, but 5 min after that no label has appeared in Q1 although cells in the next rostral segment are starting to fluoresce with dye passed from the rostral process of VMP2. Because we were thorough in giving the cells adequate time to dye couple, and thereby circumvented the animal-to-animal variation in the latency of dye transfer, we believe our measurements of the frequency of dye coupling are valid statistics that reveal a difference in the pattern of dye coupling between different sets of cells.

One subjective difference we observed in the pattern of dye coupling is that at certain times in development, dye seemed to transfer much more easily between certain pairs of cells. However, the animal-toanimal variation in the latency of dye transfer obscures this observation. We have used a new metric, the incidence of primary coupling, to minimize the variation caused by a general refractoriness to dye coupling within individual animals. We measured primary coupling by making a comparison within each injection experiment, scoring each injection for the first, or primary, pair of cells to dye couple irrespective of how long it took the dye to transfer. The incidence of primary coupling for any pair of cells was then determined by calculating the frequency, in all the injections at a particular time in development, at which that particular pair was the first to dye couple.

Ablations. We tested for indirect dye coupling between neurons by killing proposed intermediate neurons. Cells were killed by making an intracellular penetration with a Ringers-filled electrode and applying a large $( \pm 10 \mathrm{nA})$ alternating current until they showed obvious morphological abnormalities, such as swelling of the somata and curdling of the nuclei. After this treatment, labeling of adjacent cells never showed any dye coupling to the killed cells. After performing the ablation, we allowed the animals to recover for at least $30 \mathrm{~min}$ before observations of dye coupling were made.

We assayed indirect coupling by injecting Q1 with Lucifer yellow 30 
Table 1. Frequency and timing of dye coupling

\begin{tabular}{|c|c|c|c|c|c|c|c|c|c|c|}
\hline \multirow[b]{2}{*}{ Cell pair } & \multicolumn{2}{|c|}{$31 \%(n=35)$} & \multicolumn{2}{|c|}{$31.5 \%(n=31)$} & \multicolumn{2}{|c|}{$32 \%(n=42)$} & \multicolumn{2}{|c|}{$32.5 \%(n=43)$} & \multicolumn{2}{|c|}{$33 \%(n=45)$} \\
\hline & $f(\%)$ & Latency (sec) & $f(\%)$ & Latency (sec) & $f(\%)$ & Latency (sec) & $f(\%)$ & Latency (sec) & $f(\%)$ & Latency (sec) \\
\hline Q-MP & 20.7 & $130.0 \pm 22.6$ & 71.0 & $90.7 \pm 42.0$ & 95.2 & $112.9 \pm 62.5$ & 55.8 & $77.1 \pm 37.8$ & 51.1 & $163.0 \pm 136.2$ \\
\hline $\mathrm{Q}-\mathrm{CC}$ & 26.4 & $101.2 \pm 34.5$ & 100.0 & $95.8 \pm 24.6$ & 88.2 & & 97.7 & $67.3 \pm 22.6$ & 90.9 & $80.3 \pm 39.7$ \\
\hline $\mathrm{Q}-\mathrm{Q}$ & 0.0 & - & 0.0 & - & 0.0 & - & 4.9 & $67.5 \pm 10.6$ & 95.1 & $77.3 \pm 36.0$ \\
\hline Q-MP4 & 0.0 & - & 0.0 & - & 0.0 & - & 12.2 & $126.0 \pm 68.4$ & 18.8 & $131.8 \pm 41.3$ \\
\hline $\mathrm{MPl}-\mathrm{CC}$ & 80.0 & $83.0 \pm 46.8$ & 100.0 & $123.6 \pm 63.8$ & 100.0 & $86.0 \pm 75.0$ & 100.0 & $112.5 \pm 43.3$ & 100.0 & $171.4 \pm 107.1$ \\
\hline
\end{tabular}

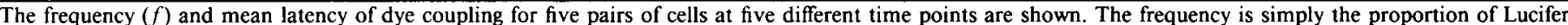

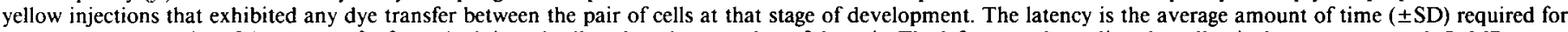

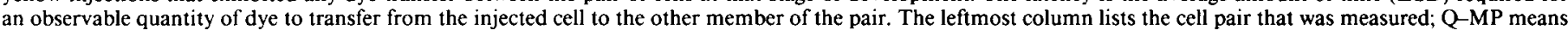

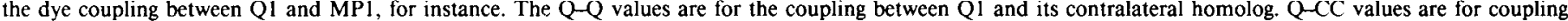
between $\mathrm{Q} 1$ and either of the corner cells, either the aCC or $\mathrm{pCC} ; \mathrm{Q} 1$ was always coupled to both, if it coupled to either.

min after ablating either the ipsilateral corner cells (18 cases) or the contralateral Q1 and Q2 (22 cases). Even after the $30 \mathrm{~min}$ recovery period, $Q 1$ failed to show any sign of coupling to any other cell, including $\mathrm{Q} 2$, in six of the corner-cell ablations and five of the contralatcral Q1 ablations. These Q1s were assumed to have been damaged by the ablation of the adjacent cell and were not considered in the analysis.

DiI injections. We dissected and mounted animals for injection exactly as for the injections with Lucifer yellow. Glass microelectrodes were filled with a $0.1-0.5 \%$ solution of $1,1^{\prime}$-dioctadecyl-3,3,3', $3^{\prime}$-tetramethylindocarbocyanine perchlorate (DiI; Molecular Probes) in either dimethyl formamide (DMF), dimethyl sulfoxide (DMSO), or $100 \%$ ethanol (Honig and Hume, 1986). A solution in DMF proved most amenable for the application of the dye, but ethanol and particularly DMSO were least damaging to cells. A continuous, small $(<0.5 \mathrm{nA})$ depolarizing current was used to generate a very slow, controlled flow of dye from the electrode tip; the electrode was then placed immediately adjacent to the cell of interest and held in place for roughly 1 min until an observable quantity of dyc had diffused over the surface of the soma.

Immediately after injection, we transferred embryos to $2 \%$ paraformaldehyde in Millonig's buffer, fixed them for an hour and washed them in $0.1 \mathrm{M}$ phosphate-buffered saline (PBS) containing $6 \mathrm{mg} / \mathrm{ml}$ glycine. A number of animals were also fixed and washed prior to labeling cells with DiI. We then observed the fixed and labeled neurons on a Bio-Rad MRC-600 confocal microscope, using a Nikon $40 \times$ objective. A typical image was assembled from four focal planes separated by $2.5 \mu \mathrm{m}$ using the ZSERIES and PROJECT commands. All of the images presented here were also processed slightly to enhance edges using the $\mathrm{C} 3 \mathrm{~A}$ convolution kernel.

Electron microscopy. We dissected embryos and fixed them in $2 \%$ paraformaldehyde and $2 \%$ glutaraldehyde in Millonig's buffer for $12-$ $24 \mathrm{hr}$. Neurons were labeled with DiI and imaged on the MRC-600 confocal microscope as described above. We then immersed the $\mathrm{cm}-$ bryos in a $0.2 \%$ solution of diaminobenzidine (DAB) in PBS and photooxidized the dye (Sandell and Masland, 1988) by illuminating the tissue with a $50 \mathrm{~W}$ mercury lamp on a Zeiss Standard microscope, using a $25 \times 0.6$ NA lens and the Zeiss wide-bandpass $(515-565 \mathrm{~nm})$ green filter set, for 30-60 min with the DAB solution changed every 10-15 min. The embryos were then prepared for electron microscopy using the techniques described in Bastiani et al. (1984).

\section{Results}

Time course of axon outgrowth

$\mathrm{Q} 1$ is a large (10-15 $\mu \mathrm{m}$ diameter), superficially positioned cell located laterally within the embryonic ganglion. $Q 1$ is surrounded by many cells, but during the period of its outgrowth, most of these cells are undifferentiated; the differentiated neurons with which Q1 may interact are diagrammed in Figure 1. Q1 has an adjacent sibling neuron, Q2, that follows the same path of axon outgrowth, but lags behind Q1 by a small percentage of development. The anterior and posterior corner cells (aCC and $\mathrm{pCC}$ ) lie medially to $\mathrm{Q} 1$ and $\mathrm{Q} 2$. The longitudinal fascicle runs between Q1/Q2 and the corner cells. The longitudinal fascicle is established by two cells, MPl and dMP2, that are located rostrally and medially to $\mathrm{Q} 1$. MP1 and $\mathrm{dMP} 2$ are among the very first neurons in the ganglion to begin axogenesis; Q1, Q2, aCC, and $\mathrm{pCC}$ all begin axogenesis $1 \%$ or $2 \%$ of development later than MP1/dMP2, and the growth cones of all six of these cells are all within simultaneous filopodial reach of one another between $31 \%$ and $32 \%$ of development. As Q1 grows, its growth cone will also contact the growth cones of two other cells: a midline neuron, MP4, and the contralateral Q1 (Fig. 1; 32.5\% and $33 \%$ ).

At $30 \%$ of embryogenesis, Q1, although it does not yet have an axon, has many filopodia that extend as far as $30 \mu \mathrm{m}$ medially, rostrally, and caudally. Laterally directed filopodia also may be present, but are shorter and more sparsely distributed. Q1 retains this relatively nondirected morphology for at least $1 \%$ of development.

By approximately $31 \%$ of development, the growth cone of the MP1 neuron approaches the Q1 soma (Fig. $2 A$, larger arrow). At this time the filopodia of $\mathrm{Q} 1$ appear more rostrally oriented and a small growth cone and axon emerge from the rostromedial quadrant of the cell.

The initial projection of Q1's axon follows the MP1/dMP2 fascicle (Fig. 3). Although the Q1 soma expresses fewer medial filopodia at this time, the axon retains many filopodia that may cross the MP1/dMP2 fascicle to intermingle with filopodia of aCC and pCC, and of MP1 and dMP2. The Q1 growth cone is very closely associated with the MP1/dMP2 fascicle (Fig. 3).

When Q1's growth cone reaches the rostrocaudal level of the MP1 soma at about $32 \%$ of development, its filopodia begin to reorient medially (Fig. 2C). The axons of the MP1 and dMP2 neurons also make a medial turn toward their cells of origin (Fig. 1), but the Q1 growth cone leaves the MP1/dMP2 fascicle and turns medially several micrometers before reaching the MPI initial segment. Q1's filopodia may reach lengths as great as 50 $\mu \mathrm{m}$, and fan out in a broad arc (Fig. 2C) that can contact the somata of MPI and the corner cells.

As Q1's growth cone turns medially, it shows morphological indications of a strong association with the MP1 soma. The growth cone is broad and flattened (Fig. $2 D$ ), and grows beneath the basement membrane a few micrometers caudal to the MP1 soma. Many filopodia extend over MPl and the growth cone may even branch away from its stereotypical medial course to extend a thick, transient process rostrally to the MPl soma. In a few instances, the labeled Q1 filopodia are so profuse and closely associated with MPl that the shape of the unlabeled MPI soma is clearly outlined. 

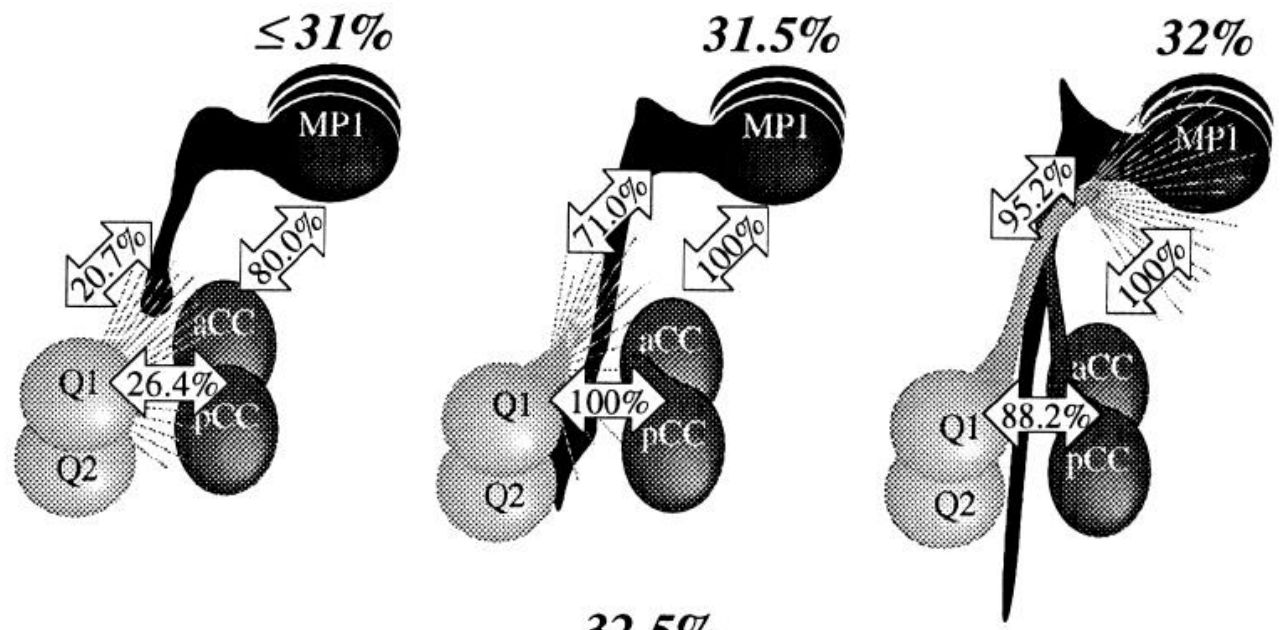

Figure 1. A diagrammatic summary of the time course of Q1 outgrowth, showing the complement of neurons with which the Q1 growth cone interacts during its outgrowth. These few cells $(Q 1, Q 2, p C C, a C C, M P 1, d M P 2, v M P 2$, $M P 4$, and the contralateral $Q 1$ ) all begin axogenesis between $30 \%$ and $32 \%$ of development, and become dye coupled to one another with a frequency given in the double-headed arrows. $31 \%$ of development, Q1 maintains a broad array of medially directed filopodia. The first instances of dye coupling between Q1 and MP1 occur before the MP1 growth cone reaches the Q1 soma, and are presumed to be via filopodial junctions. The MP1 growth cone actually contacts and becomes strongly dye coupled to the corner cells before reaching Q1. 31.5\% of development, The MP1 growth cone has contacted the Q1 soma and has been observed to associate strongly with it. Q1 has begun to extend an axon along the MP1/dMP2 pathway, and is consistently coupled to the corner cells. $32 \%$ of development, The Q1 growth cone has reached the level of the MP1 soma and has begun to turn medially. Q1's filopodia preferentially extend medially contacting the MP1 soma. $32.5 \%$ of development, The Q1 growth cone is closely apposed to the MP1 soma. Filopodia reach the midline, and we first observe a low incidence of dye coupling between Q1 and MP4, and also with the contralateral Q1. 33\% of development, Q1 has begun to fasciculate tightly with its contralateral homolog, and is also consistently dye coupled with it.

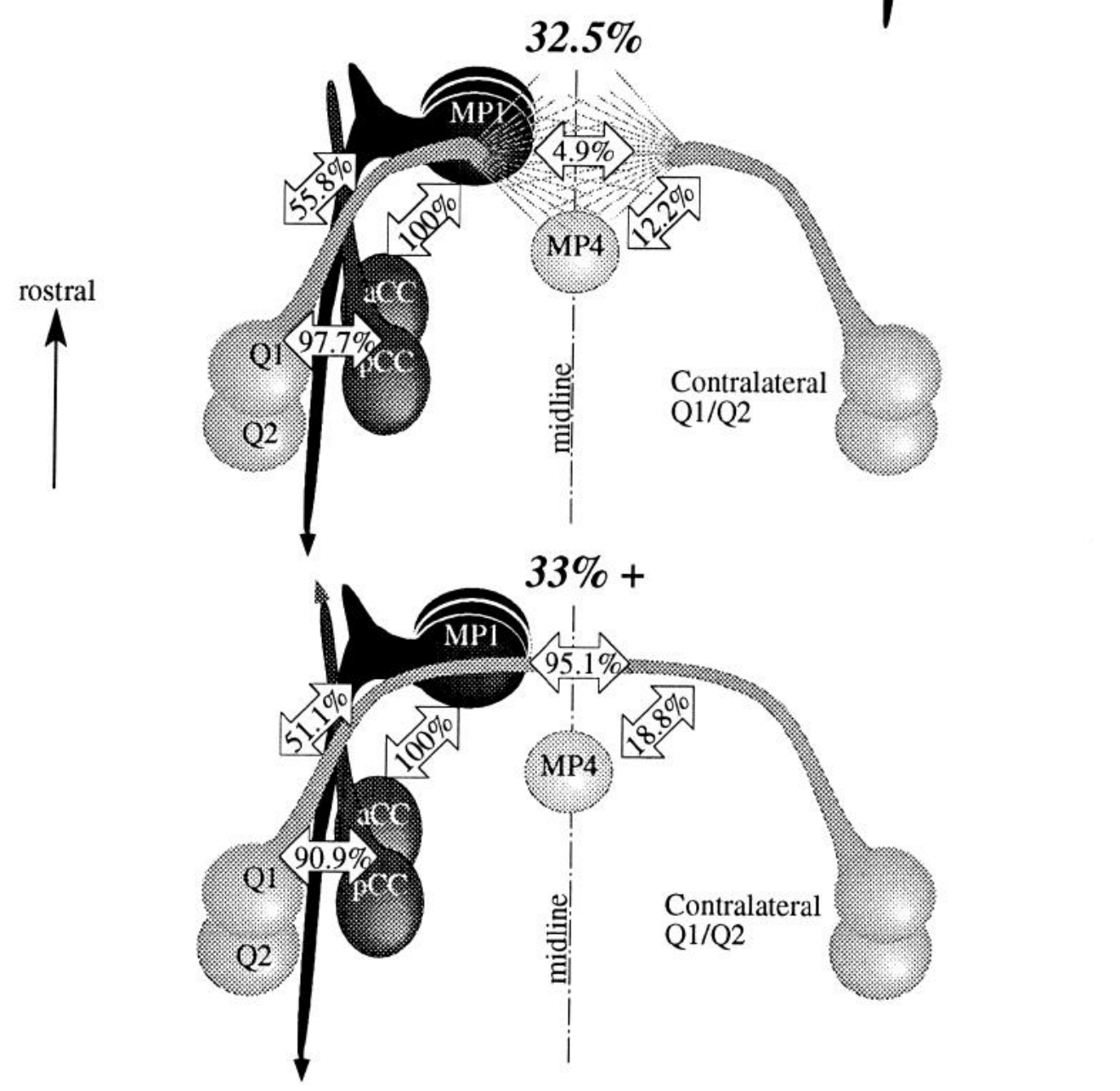

Between the MP1 soma and the midline, no superficial neuronal cell bodies or axons are present and the growth cone migrates along either basement membrane or the surfaces of as yet unidentified glia. Filopodia extend freely across the midline, and show no obvious longitudinal alignment with midline structures.

At the midline, the Q1 growth cone contacts the growth cone of its contralateral homolog and extends filopodia that overlap with neuronal cell bodies of the median neuroblast bundle and, in particular, MP4 (Fig. 1). The Q1 growth cone typically becomes much smaller and tightly apposed to the axon of its homolog. Subsequent growth is along the axon of the Q1 homolog. In contrast to the earlier loose association of the $\mathrm{Q} 1$ and MP1/dMP2 axons, the two Q1 axons are so closely apposed to one another that they cannot be discriminated from each other even with confocal microscopy. Although its growth cone expresses an unambiguous preference for the axon of the contralateral Q1, the Q1 axon continues to extend profuse filopodia (Fig. 2E).

The Q1 growth cone continues to follow its homolog laterally. Upon reaching the opposite side of the ganglion, Q1 turns and follows the initial segment of its homolog's axon caudally (Figs. 

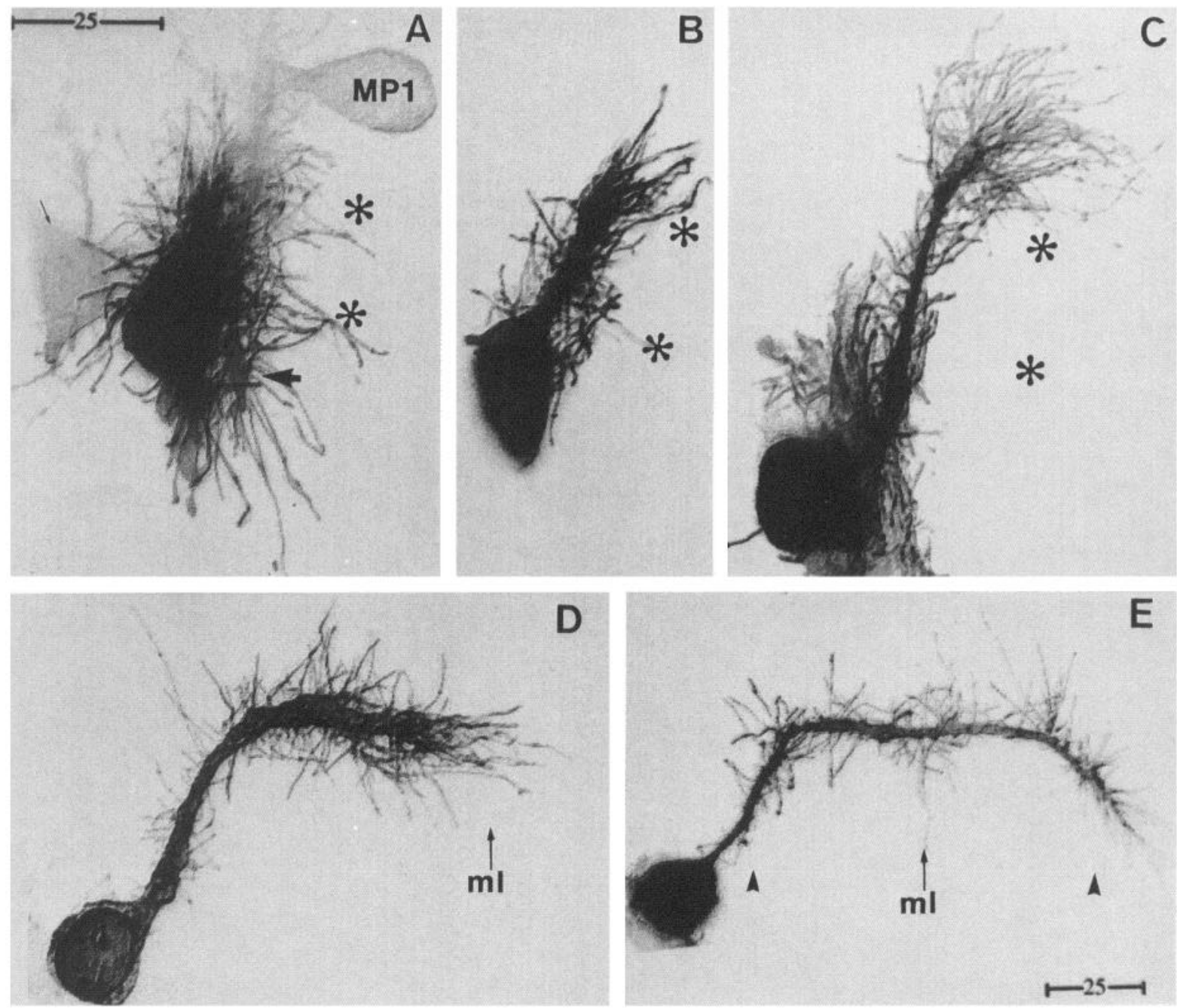

Figure 2. Time course of Q1 outgrowth as revealed by confocal microscopy of DiI labeled neurons. In this and all figures, a dorsal view of the grasshopper CNS is shown, with anterior toward the top of the page. Although these images show only the fluorescently labeled cells, the highly stereotyped configuration of the grasshopper nervous system, combined with inspection of the preparation using Nomarski optics before digitizing the images, allows us to assert the locations of many unlabeled cells with which Q1 interacts; the position of aCC and pCC are marked with asterisks in $A-C$. All panels are to the same scale (scale bar in $A$ ) except $E$, which is reduced. The location of the midline $(m l)$ is marked with arrow in $D$ and $E$, and the positions of the ipsilateral and contralateral MP1/dMP2 fascicles are marked with arrowheads in $E$. $A$, At $31 \%$ of development, Q1 begins to restrict its previously profuse filopodial arbor to extend chiefly along the path of axon outgrowth. Presumably, one of these filopodia will thicken and become the axon proper. The onset of Q1 axogenesis corresponds with the arrival of the MP1 growth cone (MP1 is lightly labeled; the larger arrow points to its growth cone) at the Q1 soma. The smaller arrow on the left points to a lightly labeled, unidentified cell (because it is very flat and dorsal, it is most likely glia). $B$, As the Q1 growth cone extends rostrally along the MP1/dMP2 fascicle (unlabeled), its filopodial arbor remains relatively restrained and directed along the path of outgrowth. $C$, At approximately $32 \%$ of development, the Q1 growth cone reaches the level of the MP1 soma, and abruptly takes on a different character. A dense mat of filopodia extends medially over a broad area. $D$, The growth cone of Q1 reaches the midline at 33\% of development. After passing the MP1 soma, the Q1 growth cone migrates across 10-20 $\mu \mathrm{m}$ of basement membrane or glial surface unoccupied by other neurons or axons to contact the midline neuron MP4 and the growth cone of its contralateral homolog. $E$, By $34 \%$ of development, the growth cone has reached the opposite side of the ganglion and has begun to turn caudally. The Q1 growth cone is greatly reduced in size while fasciculating with its contralateral homolog to reach the contralateral MP1/dMP2 pathway (both the ipsilateral and contralateral MP1/dMP2 pathways are marked with arrowheads). Not only is the growth cone smaller, but filopodia are more restrained and closely restricted to the prospective path of outgrowth. Upon reaching the contralateral MP1/dMP2 fascicle, the growth cone transfers from the Q1 axon to the MP1/dMP2 fascicle with no apparent changes in morphology. (This panel is of a slightly smaller scale than the other panels in this figure.)

$2 E$, 4). At this time, its filopodia are more posteriorly directed, and extend along the longitudinal pathway, its future course. The Q1 growth cone continues its growth caudally by shifting to the MP1/dMP2 fascicle, where it obliquely crosses the contralateral Q1 axon (Fig. 4E). The growth cone continues to extend along the MP1/dMP2 fascicle as far as two segments caudally before Q1 dies, between $40 \%$ and $45 \%$ of development.

\section{Temporal pattern of dye coupling}

During the course of its outgrowth, Q1 becomes dye coupled to a limited and specific set of neurons (Fig. 1). Although its widespread filopodia contact many undifferentiated cells and glia, Q1 and Q2 are directly dye coupled to only five sets of neurons: (1) the ipsilateral aCC and pCC, (2) the ipsilateral MP1 and 

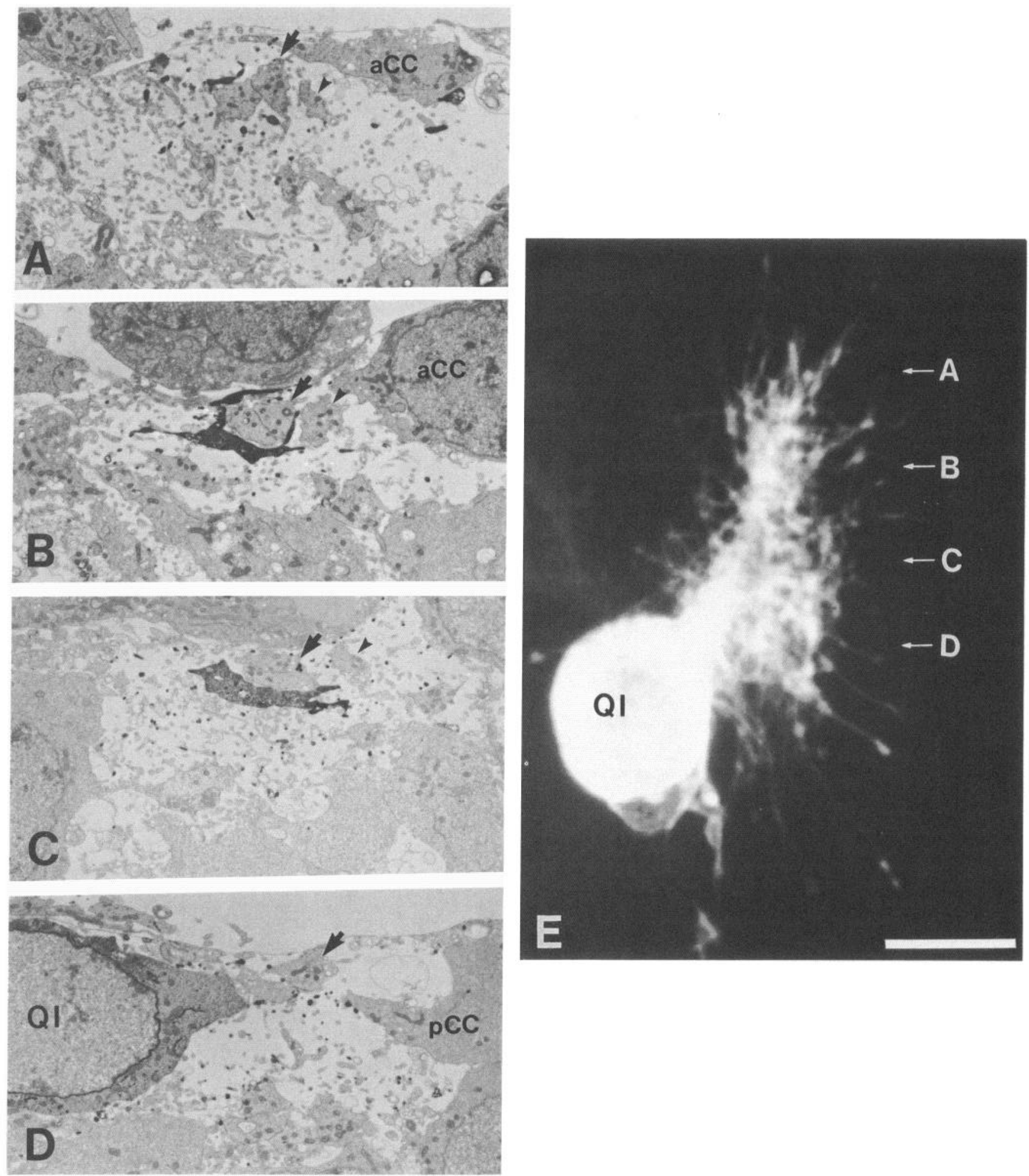

Figure 3. The Q1 growth cone is closely associated with the ipsilateral MP1/dMP2 fascicle. These electron micrographs $(A-D)$ were prepared from the DiI-labeled Q1 neuron shown in $E$. The DiI was photo-oxidized with DAB and osmicated to produce the dark, electron-dense profiles in $A-D$. The level of the sections marked $A-D$ in $E$ correspond to $A-D$. In all of the electron micrographs, the MP1 and dMP2 axons (which together pioneer the MP1/dMP2 fascicle) are indicated with arrows and the adjacent axon of the posterior corner cell ( $p C C)$ is indicated with arrowheads. All sections are transverse, with dorsal to the top of the page and medial to the right. The MP1 and dMP2 axons pass in close proximity to the Q1 soma $(D)$. At this stage in development, the only axons present in the MP1/dMP2 fascicle are those of MP1 and dMP2. The initial projection of the Q1 axon is directly adjacent to the MP1/dMP2 fascicle $(C)$, and the Q1 growth cone can be seen to almost completely enwrap the fascicle $(B)$. Filopodia extending rostrally from the Q1 growth cone also retain contact with the MP1/dMP2 fascicle $(A)$. Magnification $(A-D), 4700 \times$; scale bar $(E), 10 \mu \mathrm{m}$. 
dMP2 neurons, (3) the MP4 neuron at the midline, (4) the contralateral Q1 and Q2, and (5) a previously unidentified neuron located caudally and adjacent to the Q1/Q2 pair that we have named PQ. PQ was dye coupled with Q1 in $12 \%$ of the Q1 injections, but will not be considered further in this article. Its cell body is located caudal to $Q 1$ and is not contacted by Q1's growth cone except, perhaps, immediately after axogenesis. The PQ axon extends caudally along the MP1/dMP2 fascicle and also does not interact with $\mathrm{Q} 1$ or contribute to the formation of the posterior commissure.

Dye diffused rapidly from injected cells to cells with which they were coupled. The first coupled cells were typically visible within 1-2 min; all of the cells that are directly coupled to the injected cell were labeled within $5 \mathrm{~min}$. Dye injections for longer than 10-15 min showed no further spread of dye, however, either because of cumulative damage to the cell or embryo, or because of progressive fixation of the dye to elements in the cytoplasm (J. S. Eisen, personal communication).

Dye coupling between cells can occur via filopodia. Q1 and MP1 are dye coupled before the MPl growth cone reaches the Q1 soma, and before Q1 begins axogenesis. Dye coupling was also seen between Q1 and its contralateral homolog before either growth cone reached the midline (Fig. 1).

\section{Dve coupling between $Q I$ and the corner cells}

Q1 expresses a robust pattern of dye coupling with the corner cells throughout the course of its development (Figs. 1, 5; Table 1). Dye coupling was first observed shortly after axogenesis at about $31.5 \%$ of embryogenesis. This initial coupling is via filopodia-filopodia or filopodia-somata junctions, because the growth cones have not yet met. Despite this restriction to filopodial connections, dye passed with remarkable reliability (100\%) from Q1 to the corner cells. Later in development, after their growth cones contact and pass each other, Q1 and the anterior and posterior corner cells continue to maintain their strong and consistent coupling.

\section{Dye coupling between $Q 1$ and MPI}

Coupling between MP1 and Q1 is a more variable phenomenon. Over all of development, dye consistently passes from Q1 to the corner cells before it passes to MP1 except at two specific developmental stages (Fig. 6, Table 2). At the time the MP1 growth cone contacts the Q1 soma (31.5\% of embryogenesis), the $\mathrm{MPl}-\mathrm{Q} 1$ coupling is stronger than the $\mathrm{CC}-\mathrm{Q} 1$ coupling $83.3 \%$ of the time. Similarly, when the Q1 growth cone extends over the MP1 soma (32.5\% of embryogenesis), dye passes more rapidly from $\mathrm{Q} 1$ to $\mathrm{MP} 1$ than from $\mathrm{Q} 1$ to $\mathrm{CC} 28.2 \%$ of the time. Coincident with these observed peaks in the strength of primary coupling between Q1 and MP1, we also observed that the growth cone was enlarged and closely apposed to the cell body. In these instances, we suspect that there is a transient increase in either the efficacy or number of gap junctions between MP1 and Q1.

At other times, when growth cones are not directly apposed to the somata, dye is consistently transferred from $\mathrm{Q} 1$ to the corner cells before it passes to MP1. One extreme interpretation of this observation would be that the coupling between MP1 and $Q 1$ could be nonexistent at these times, and the dye is passed indirectly, via the corner cells. We tested this possibility by killing both corner cells, thus removing the putative intermediates from the circuit. In two of the five cases in which we killed the corner cells at $31 \%$ of development, dye did pass from Q1 to MP1. In four of seven cases in which the corner cells were killed at $31.5 \%$ of embryogenesis, a time at which we observed an increased coupling strength, we also saw direct coupling between Q1 and MP1. In both of these experiments, the frequency of coupling is less than that observed in unperturbed animals, and may result from damage to the cells; that the cells exhibit any coupling at all, however, indicates that direct coupling between these cells is not prohibited.

Although these results clearly indicate that direct coupling occurs and is retained between Q1 and MPl with at least some small frequency, the overall dye coupling between Q1 and MP1 is less robust than that between $\mathrm{Q} 1$ and the corner cells. It is not likely, however, that this reduced frequency is due to some intrinsic refractoriness or fragility of the gap junctions made by MP1. At the same stage of development, MP1 couples strongly and with near $100 \%$ efficiency to the corner cells (Figs. 1, 5).

\section{Dye coupling across the midline}

Q1's filopodia first reach the midline at $32.5 \%$ of development, although the growth cone itself does not reach the midline until $33 \%$ of development (Fig. 1). Even at $32.5 \%$ of devclopment we see a low frequency of coupling between $Q 1$ and the midline neuron MP4, and the contralateral Q1. By the time the growth cone reaches the midline, the coupling between the pair of Q1s is strong and consistent. The observed coupling between $Q 1$ and MP4 remains variable, with a frequency under 20\% (Fig. 5).

\section{Dye coupling with contralateral neurons}

The contralateral neuron with which Q1 couples most strongly is clearly its contralateral homolog. In addition, however, Q1 is often observed to be dye coupled to a number of other contralateral neurons, in particular, the contralateral corner cells. The frequency of observed coupling is low. At 33\% of development, before the $\mathrm{Ql}$ growth cone reaches the contralateral corner cells, dye coupling between $\mathrm{Q} l$ and the contralateral $\mathrm{aCC}$ and pCC must be indirect and has a frequency of $23.4 \%$; at $34 \%$ of development, when the Q1 growth cone is in contact with the corner cell somata, the frequency of coupling is still low, at $21.8 \%$. These observations are compatible with the idea that the coupling to contralateral neurons other than $Q 1$ is indirect, via the contralateral Q1. As further corroboration, ablating the contralateral Q1 at $34 \%$ of development abolished all coupling with other contralateral neurons in $100 \%$ of 17 cases.

Q1 does not seem to dye couple to its ultimate target, the contralateral MPl neuron, even after it has begun to fasciculate with it. Of 12 instances in which the labeled Q1 growth cone was clearly growing caudally on the MPI/dMP2 fascicle, only one showed any dye coupling with MP1, and that was $4.5 \mathrm{~min}$ after injection, $3 \mathrm{~min}$ after the contralateral Q1 had become labeled.

\section{Discussion}

The navigation of a growth cone along a specific and complex trajectory must require some recognition and interaction with elements in its environment. We have followed the outgrowth of one neuron, the commissural interneuron Q1, and identified a small set of stereotyped interactions that may play a role in guiding its growth cone, and perhaps also in "reprogramming" Q1's target choice.

\section{Initial outgrowth}

Q1 initially extends an axon rostrally, in parallel with the descending longitudinal axon of the MP1 neuron (Figs. 1, 3). Be- 

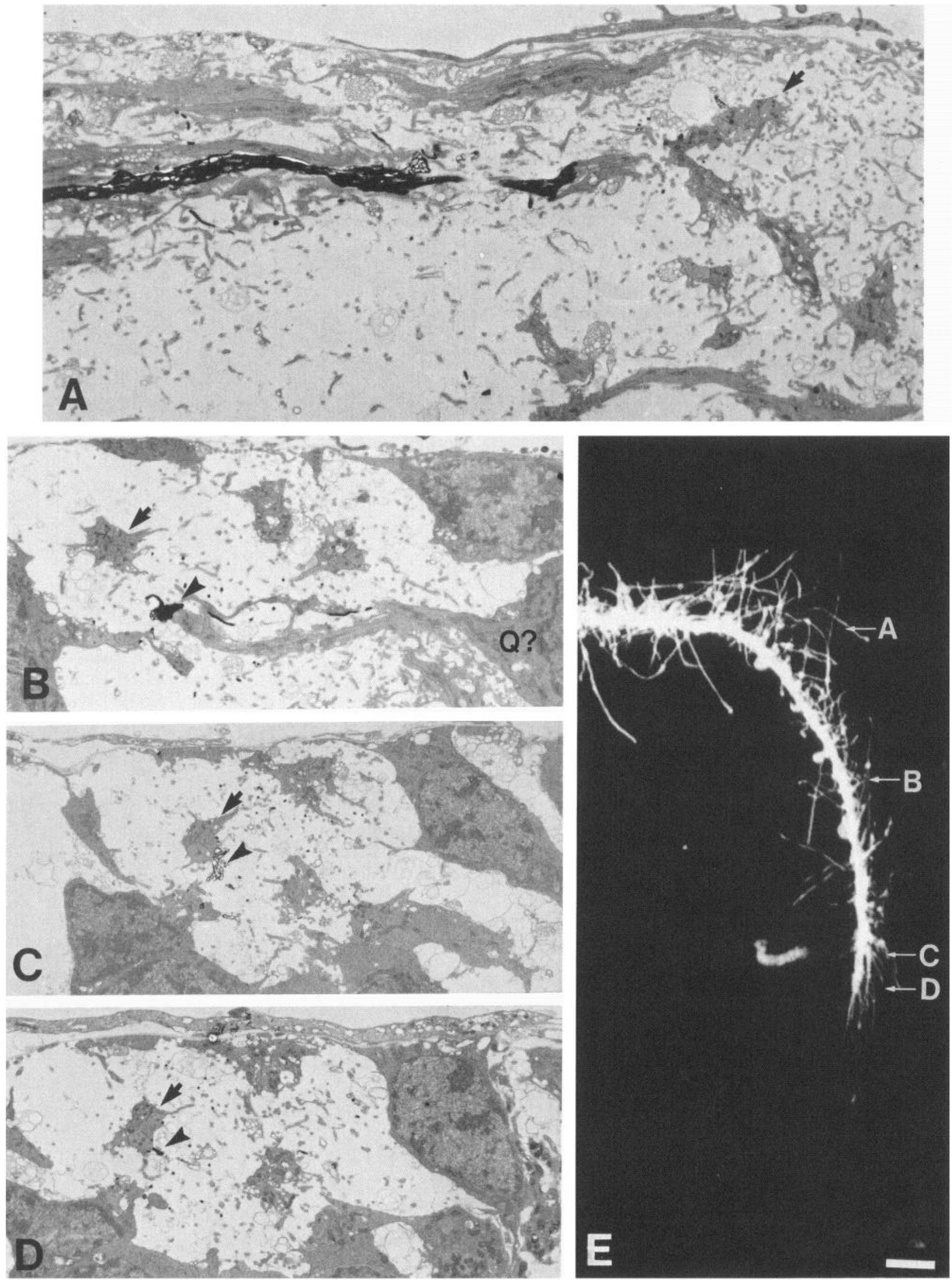

Figure 4. The Q1 growth cone migrates in the contralateral MP1/dMP2 fascicle. These electron micrographs $(A-D)$ were prepared from the DiIlabeled Q1 axon shown in $E$. The DiI was photo-oxidized with DAB and osmicated to produce the dark, electron-dense profiles in $A-D$. The position of the labeled Q1 growth cone is indicated in $B-D$ with an arrowhead, and the MP1 and dMP2 axons are indicated with an arrow. The 
fore extending an axon, though, Q1 seems to wait for $1 \%$ or more of development in an unoriented state. It possesses extensive filopodia that radiate rostrally, medially, and caudally, but only after the MPl growth cone contacts the filopodia or soma do the filopodia begin to restrict themselves more specifically to the appropriate rostral direction. The correlation in timing suggests that MPl may play a role in defining Q1's initial polarity.

We observed another suggestive correlation in that Q1 initiates axogenesis shortly after the MPl growth cone contacts its soma, and that we see a simultaneous transient increase in dye coupling between the MP1 growth cone and the Q1 soma (Fig. 6 ). It has been suggested that the abrupt transfer of small ions such as calcium through gap junctions could inhibit or trigger axogenesis (Bentley et al., 1991). A pulse of calcium from the MPl growth cone, for example, may be the stimulus to trigger axon outgrowth in $\mathrm{Q} 1$.

Alternatively, the interactions we observe between MPI and Q1 might not be important to Ql's development at all, but actually might be important cues for MPl's normal development instead. It has not escaped our notice that $\mathrm{Q} 1 / \mathrm{Q} 2$ and pCC/aCC very neatly bracket the prospective longitudinal pathway (Fig. 1), and could conceivably act like channel markers to guide the MPl growth cone along its correct path.

\section{Medial turn}

In addition to closely following the MPl axon, Ql's growth cone responds dramatically to contact with the MP1 soma. Q1 turns medially shortly after its filopodia contact the MP1 soma, and the Q1 growth cone undergoes characteristic morphological changes as it grows over the MPl soma. The growth cone may flatten over the surface of the soma or extend an alternate branch, and splay a dense mat of filopodia over and around the soma. These morphological changes suggest that $Q 1$ is trying to increase contact with the MPl soma, and indicate a selective affinity (Bastiani el al., 1984).

We also observed a transient increase in dye coupling between Q1 and MP1 as the growth cone enwrapped the soma (Fig. 6). This increases in coupling could be a simple consequence of an increase of surface area in contact; alternatively, MPl is a good candidate for a guidepost neuron that induces Q1's medial turn, and perhaps the dye coupling is an important and specific informative interaction.

\section{Growth to the midline}

At the same time that Q1's growth cone is adjacent to the MP1 soma, Q1 is extending filopodia that contact a midline neuron, MP4, as well as filopodia of its contralateral homolog. Upon reaching the midline, Q1 fasciculates very tightly with the contralateral Q1 axon, and follows it across the midline to the contralateral longitudinal pathway (Fig. 1).

Other than occasional filopodial alignment with the midline (Fig. $2 E$ ) and the strong fasciculation with the contralateral Q1, we observed no obvious interactions with midline structures.
Table 2. Incidence of primary coupling

\begin{tabular}{lclllc} 
& $\begin{array}{l}31.0 \% \\
(n=15)\end{array}$ & $\begin{array}{l}31.5 \% \\
(n=18)\end{array}$ & $\begin{array}{l}32 \% \\
(n=22)\end{array}$ & $\begin{array}{l}32.5 \% \\
(n=39)\end{array}$ & $\begin{array}{l}33 \% \\
(n=36)\end{array}$ \\
\hline Q-MP & 0.00 & $83.3 \%$ & $0.0 \%$ & $28.2 \%$ & $5.6 \%$ \\
Q-CC & $100.0 \%$ & $16.7 \%$ & $100.0 \%$ & $71.8 \%$ & $44.4 \%$ \\
Q-Q & - & - & - & $0.0 \%$ & $50.0 \%$ \\
Q-MP4 & - & - & - & $0.0 \%$ & $0.0 \%$
\end{tabular}

This table presents a subset of the data in Table 1 ; only those experiments in which Q1 was injected with Lucifer yellow are included. For each of the four cells listed (MP1, the corner cells, the contralateral Q1, and MP4) at five different developmental stages, these values answer the question, "How often was this cell the first to become dye coupled to Q1?" Because the latency of dye transfer (Table 1) was subject to a great deal of day-to-day and animal-to-animal variability and so was a poor measure of the strength of dye coupling between cells, this metric was calculated to compare the timing of dye transfer from Q1 to other cells within a single injection experiment, and so is a measure of the relative strength of the coupling to Q1.

This is in marked contrast to the reports of vital interactions in vertebrates between commissural neurons and a non-neuronal midline structure, the floorplate (Placzek et al., 1988; Kuwada et al., 1990). An analogous glial structure has also been reported to be a critical element in commissure formation in Drosophila (Jacobs and Goodman, 1989; Klämbt et al., 1991). Such interactions may be hidden from the techniques used in this work, because we have observed no instances of dye coupling between neurons and non-neuronal cells, and because the intense fasciculation between the two Q1's may mask any other substrate interactions at the midline. We intend to pursue the matter of non-neuronal substrates at the midline using antibodies that reveal glial organization (Carpenter and Bastiani, 1990, 1991), and a more direct search using Lucifer yellow injection and ablation techniques. In addition, we can unmask alternative Q1 growth cone behaviors at the midline by ablating the contralateral Q1.

\section{Selection of the contralateral MPI/dMP2 fascicle}

A simple model of $\mathrm{Q} 1$ outgrowth is that it simply hops to progressively more adhesive substrates. Q1's growth could be imagined as a series of leaps from one moderately adhesive substrate, the ipsilateral longitudinal pathway, to a more adhesive intermediate target, the MPl soma, and finally to the most preferred substrate, the axon of the contralateral Q1. One flaw of this model is that finally the Q1 growth cone arrives at an MP1/ dMP2 fascicle, initially the least preferred substrate, and abandons the contralateral Q1 axon to follow it. We assume that either MPl or Q1 has changed by $34 \%$ of development; either the MP1 axon has become a more attractive substrate, or Q1's substrate preference has been respecified during the course of its outgrowth.

One possible way that substrate preferences could change is simply as a consequence of maturation. Neurons could carry an intrinsic program of expression of cell surface proteins that changes automatically with time, without any need for cues in

level of the sections marked $A-D$ in $E$ correspond to $A-D$. $A$, The $\mathrm{Q} 1$ axon in a tangential section as it crosses in the posterior commissure. At this time, Q1 is fasciculating with at least three other axons: its ipsilateral sibling, Q2, and the contralateral Q1 and Q2 axons. $B, \mathrm{Q} 1$ maintains this contact with the contralateral Q neurons as it turns caudally. In this section, the Q1 axon is seen in contact with the initial segment of an unidentified member of the neuroblast 7-4 family (labeled Q?; it is either Q1 or Q2). $C$ and $D$, After growing beyond the somata and axons of the contralateral $\mathrm{Q}$ neurons, the Q1 growth cone fasciculates with the contralateral MP1/dMP2 fascicle. The Q1 growth cone at this time is relatively small and its filopodia nlarrowly focused, compared to its morphology when growing on the ipsilateral MP1/dMP2 pathway (Fig. 3). The Q1 growth cone (arrowhead) is visible as a vesiculated mass located immediately laterally and ventrally to MP1/dMP2 in $C$; it is reduced to a small process directly adjacent to MP1/dMP2 in $D$. Magnification $(A-D), 4700 \times$; scale bar $(E), 10 \mu \mathrm{m}$. 


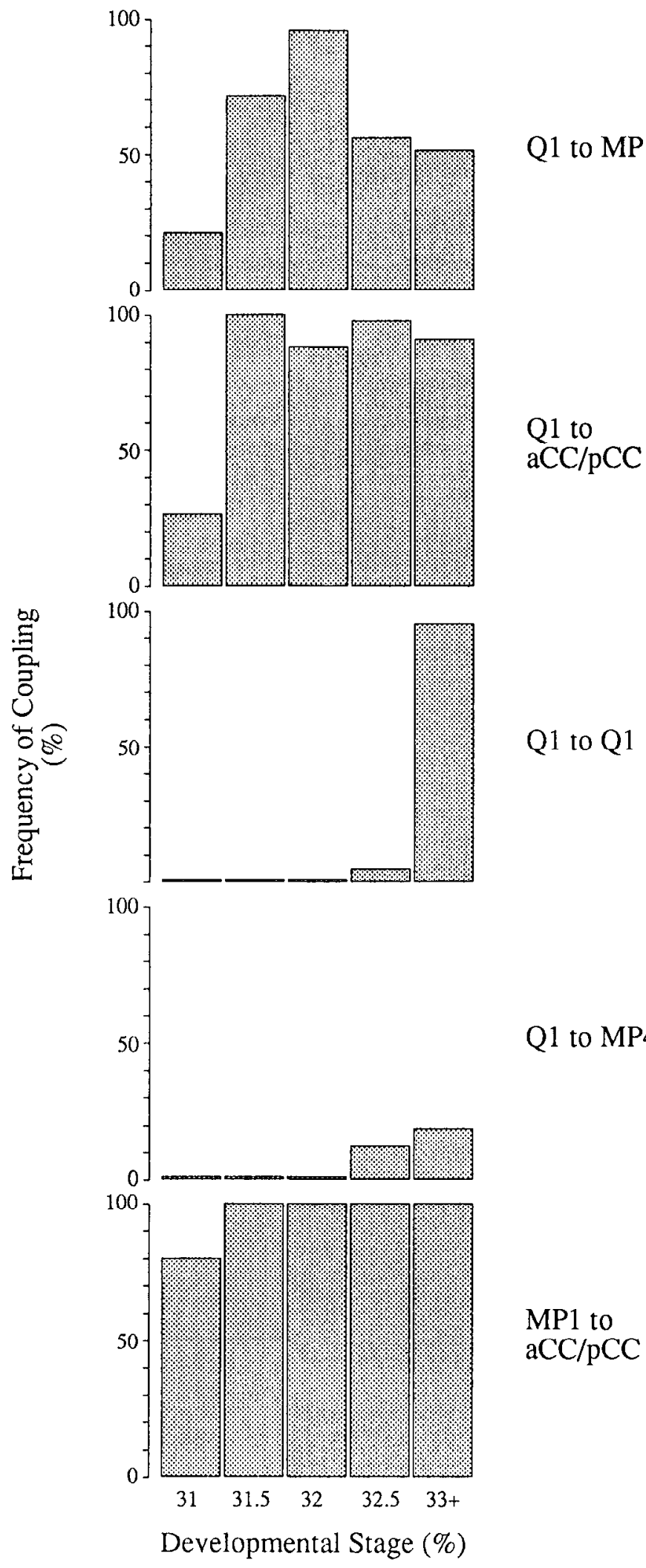

Figure 5. A graph of the frequency of dye coupling over time between pairs of neurons. Coupling was scored as present even if it took $5 \mathrm{~min}$ or more for dye to pass from the injected cell to another cell; because dye typically diffused to adjacent, directly coupled neurons within 2 min, it is entirely possible that many indirectly coupled neurons have crept into this data set. We observed three essentially different patterns of dye coupling. The coupling between Q1 and MP1 was variable over

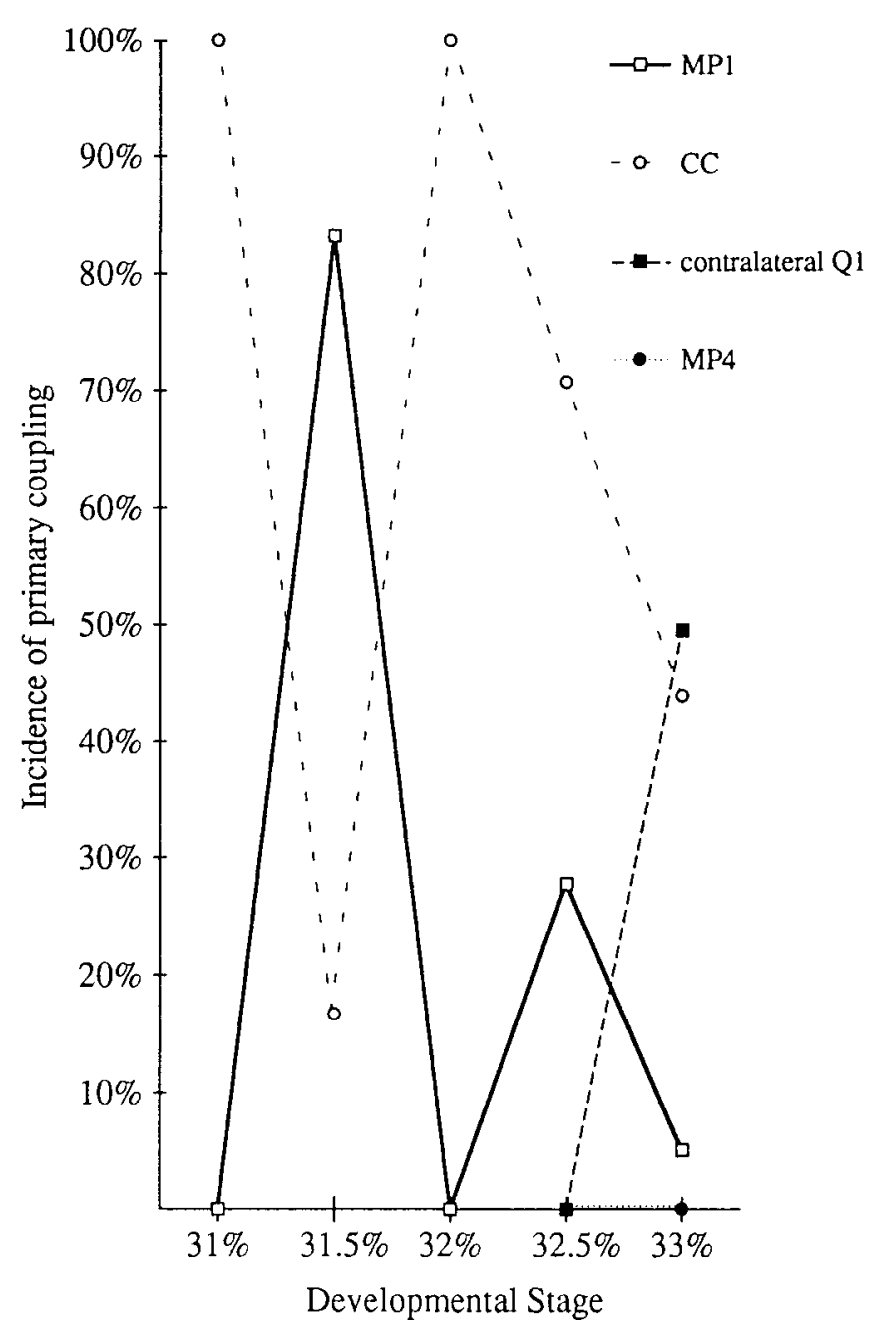

Figure 6. A graph of the incidence of primary coupling from Q1 to MP1, the corner cells, MP4, and the contralateral Q1. We have defined primary coupling as those instances where the specified cell was unambiguously the first to dye couple to Q1. If a ccll is stated to have a $0 \%$ incidence of primary coupling to Q1 at a particular stage, that does not imply that there was no coupling, but rather that in every injection some other cell was dye coupled to Q1 earlier. In these instances, the dye coupling could be indirect. If a cell is the first to couple to Q1, however, we can rule out the possibility of indirect coupling because no other intermediary cell is labeled with dye. We saw two peaks in the incidence of primary coupling between Q1 and MP1, at 31.5\% and $32.5 \%$ of development. These time points correspond, respectively, to the time at which the MP1 growth cone contacts the Q1 soma, and the time at which the Q1 growth cone contacts the MP1 soma.

time; the frequency peaked as the Q1 growth cone was extending along the MP1 axon, and as Q1 filopodia contacted the MP1 soma. On the other hand, the coupling from Q1 to the corner cells, from Q1 to the contralateral Q1, and from MP1 to the corner cells was very reliable over time. Once these pairs of cells met, they became dye coupled and retained their connections $90 \%$ of the time or better. The coupling between Q1 and MP4, like that between Q1 and MP1, was also inconsistent, but was always at a very low level, never exceeding $20 \%$. Note that this variable frequency does not necessarily mean that the cells are coupled in only $20 \%$ of the animals; the coupling could be very consistent but occur for only a brief period of time, such that our brief snapshot of the state of coupling misses the event $80 \%$ of the time. 
the environment to trigger the changes. Alternatively, one or more of the interactions the growth cone makes en route could be indispensable in reprogramming the cell to respond appropriately to subsequent interactions. If true, we expect that removing one of the intermediate interactions (such as the Q1 growth cone to MP1 soma contact) might not only cause aberrations in pathfinding, but could also induce the growth cone to fail to recognize its normal target (such as the contralateral $\mathrm{MP1/dMP2} \mathrm{fascicle).}$

One curious feature of Q1's fasciculation with the contralateral MP1/dMP2 fascicle is that, although dye coupling is a consistent and persistent feature of all of Q1's earlier interactions during pathfinding, QI and the contralateral MPl showed no observable direct coupling at any time. It has been shown in vertebrates that dye coupling may not be an essential part of pathfinding (Holt, 1989). Therefore, an absence of dye coupling is not surprising in itself. The absence does indicate, however, that coupling is not blind and promiscuous, and so highlights the unknown significance of the consistent early coupling we have observed. One consistent correlation in the pattern of dye coupling is that Q1 directly dye couples only with cells with which it has had an opportunity to have a growth cone-growth cone interaction. By 34\% of development, many new neurons have arisen and their growth cones have contacted the Q1 soma and axon, but none have been observed to become dye coupled to Q1. Direct dye coupling is restricted to small pools of neurons that begin outgrowth at similar stages of development.

\section{What is the role of dye coupling?}

One potential mechanism for reprogramming growing neurons may be by transfer of cytoplasmic factors via gap junctions. However, it is difficult to extrapolate specific intercellular interactions from the pattern of dye coupling we have observed. Several of the dye coupling interactions, such as between Q1 and the corner cells or between the corner cells and MP1, appear to be maintained at a continuous and uniform level throughout development. There are no apparent changes in the pattern of dye coupling between these cells that can be correlated with events in the navigation of growth cones. It may be that there are specific unseen changes in the types or quantities of molecules passing through these persistent gap junctions. Possibly gap junctions play no direct role in growth cone guidance at all, but instead are involved in maintaining a uniform distribution of cytoplasmic ions, for instance, in a pool of growing cells. Their role, then, would be in general homeostasis and growth.

However, the coupling between Q1 and MP1 (and Q1 and MP4) is more complex, and changes with time. We observed two peaks in the strength of dye coupling that coincided with growth cone-soma contacts (Fig. 6), although some degree of coupling between Q1 and MP1 was maintained throughout early development (Fig. 5). We interpret these observations as suggesting that Q1 and MP1 make strong, selective junctions at their growth cones to cell bodies they contact, but that these junctions are not necessarily robustly maintained after the growth cone has extended beyond the soma.

One function of transient dye coupling between migrating growth cones and encountered cell bodies is the transfer of cytoplasmic factors that may influence growth rates and pathfinding (Kater et al., 1988). Just as cell-surface receptors could be used by the growth cone to sample molecules in the extracellular environment and on the surfaces of other cells, the formation of relatively indiscriminate gap junctions with other neurons in its path could allow growth cones to sample the informationrich intracellular environment as well. The transient gap junctions we have observed may indicate that $Q 1$ is querying MP1 about its internal state; whether the information returned by MP1 is used by Q1 in making any growth decisions could be determined by removing MPI's opportunity to reply, either by killing MP1 or blocking dye coupling with the appropriate molecular reagents.

Preliminary results from experiments in which MPl is ablated shortly before it dye couples with Q1 (Myers and Bastiani, unpublished observations) have revealed no consistent effect on pathfinding by the QI growth cone. Similarly, attempts to remove dye coupled elements in the zebrafish have not produced any significant or consistent alterations in neuronal pathfinding (Eisen et al., 1989). One interpretation of these results is that dye coupling may be an insignificant epiphenomenon: perhaps developing neurons dye couple promiscuously with their differentiated neighbors, so the appearance of patterns of dye coupling is a consequence but not a cause of patterns in development.

We would argue, however, that the data do not rule out the possibility of subtle or indirect effects of gap-junctional communication on pathfinding. Kater et al. (1988) have shown that axogenesis can be initiated by changes in the cytoplasmic calcium concentration, and that calcium concentration can also influence growth cone migration rates. In a simple nervous system that lacks a great deal of cellular redundancy, variation in migration rates could result in a growth cone missing a critical interaction at an appropriate time; delays of a few percent of development can lead to a failure by growth cones to find or recognize normal cues, and cause subsequent mismigration (Doe et al., 1986). One role of gap-junctional communication, then, could be in synchronizing growth in a population of interacting neurons. In the specific case of $Q 1$, the pattern of gap-junctional communication would synchronize development across the midline. The MPls on each side of the ganglion, the first neuron in this system to differentiate, arise from the terminal division of a single midline precursor (Bate, 1976; Doe and Goodman, 1985), and are presumably synchronized by their necessarily common time of origin. The MPls separate, migrate laterally, and commence axogenesis. We predict that they would then contact the Q1 on each side of the ganglion simultaneously. If the transfer of cytoplasmic growth factors triggers axogenesis in the two Q1s, it would increase the likelihood that both Q1s in a ganglion would begin outgrowth simultaneously, and it would minimize the disparity in the time of arrival of their growth cones at the midline. Ablating MP1/dMP2 before they can contact Q1/Q1 should produce an increased likelihood that the two Q1s in the ganglion would not arrive at the midline at the same time. Because the Q1 growth cone relies on timely contact with its contralateral homolog at the midline for proper pathfinding (Myers and Bastiani, 1992), this synchronization may be an important factor in increasing the fidelity of pathfinding.

\section{References}

Bastiani MJ, Raper JA, Goodman CS (1984) Pathfinding by neuronal growth cones in grasshopper embryos. III. Selective affinity of the G growth cone for the P cells within the A/P fascicle. J Neurosci 4:23112328.

Bate CM (1976) Embryogenesis of an insect nervous system. I. A map 
of the thoracic and abdominal neuroblasts in Locusta migratoria. Embryol Exp Morphol 35:107-123.

Bentley D, Caudy M (1983a) Pioneer axons lose directed growth after selective killing of guidepost cells. Nature 304:62-65.

Bentley D, Caudy M (1983b) Navigational substrates for peripheral pioneer growth cones: limb-axis polarity cues, limb-segment boundaries and guidepost neurons. Cold Spring Harbor Symp Quant Biol 48:573-585.

Bentley D, Keshishian H (1982) Pathfinding by peripheral pioneer neurons in grasshoppers. Science 21 8:1082-1088.

Bentley D, Keshishian H, Shankland M, Toroian-Raymond A (1979) Quantitative staging of embryonic development of the grasshopper, Schistocerca nitens. Embryol Exp Morphol 54:47-74.

Bentley D, Guthrie PB, Kater SB (1991) Calcium ion distribution in nascent pioneer axons and coupled preaxonogenesis neurons in situ. J Neurosci 11:1300-1308.

Blair SS, Palka J (1989) Mosaic Drosophila wings reveal regional heterogeneity in the guidance of ectopic axons. J Neurobiol 20:55-68.

Bovolenta P, Dodd J (1990) Guidance of commissural growth cones at the floor plate in embryonic rat spinal cord. Development 109: $435-447$.

Bovolenta P, Mason CA (1987) Growth cone morphology varies with position in the developing mouse visual pathway from retina to first targets. J Neurosci 7:1447-1460.

Bray D, Chapman K (1985) Analysis of microspike movements at the neuronal growth cone. J Neurosci 5:3204-3213.

Burmeister D, Goldberg D (1988) Micropruning: the mechanism of turning of Aplysia growth cones at substrate borders in vitro. J Neurosci 6:1781-1795.

Carpenter EM, Bastiani MJ (1990) Expression and characterization of nervous system antigens in grasshopper embryos. Soc Neurosci Abstr 16:303.

Carpenter EM, Bastiani MJ (1991) Developmental expression of REGA-1, a regionally expressed glial antigen in the central nervous system of grasshopper embryos. J Neurosci 11:277-286.

Caveney S (1985) The role of gap junctions in development. Annu Rev Physiol 47:319-335

Cox EC, Müller B, Bonhoeffer $\Gamma$ (1990) Axonal guidance in the chick visual system: posterior tectal membranes induce collapse of growth cones from the temporal retina. Neuron 2:31-37.

Doe CQ, Goodman CS (1985) Early events in insect neurogenesis. I. Developmental and segmental differences in the pattern of neuronal precursor cells. Dev Biol 111:193-205.

Doe CQ, Bastiani MJ, Goodman CS (1986) Guidance of neuronal growth cones in the grasshopper embryo. IV. Temporal delay experiments. J Neurosci 6:3552-3563.

Eisen JS, Pike SH, Debu B (1989) The growth cones of identified motoneurons in embryonic zebrafish select appropriate pathways in the absence of specific cellular interactions. Neuron 2:1097-1104.

Gundersen RW, Barret JN (1979) Neuronal chemotaxis: chick dorsal root axons turn toward high concentration of nerve growth factor Science 206:1079-1080.

Guthrie SC, Gilula NB (1989) Gap junctional communication and development. Trends Neurosci 12:12-16.

Guthrie SC, Turin L, Warner AE (1988) Patterns of junctional communication during development of the early amphibian embryo. Development 103:769-783.

Hammarback JA, Palm SL, Furcht LT, Letourneau PC (1985) Guidance of neurite outgrowth by pathways of substratum-adsorbed laminin. J Neurosci Res 13:213-220.

Holt CE (1989) A single-cell analysis of early retinal ganglion cell differentiation in Xenopus: from soma to axon tip. J Neurosci 9:31233145 .

Honig M, Hume RI (1986) Fluorescent carbocyanine dyes allow living neurons of identified origin to be studied in long-term cultures. J Cell Biol 103:171-188.

Jacobs JR, Goodman CS (1989) Embryonic development of axon pathways in the Drosophila CNS. I. A glial scaffold appears before the first growth cones. J Neurosci 9:2402-2411.

Kapfhammer JP, Raper JA (1987) Collapse of growth cone structure on contact with specific neurites in culture. J Neurosci 7:201-212.

Kater SB, Mattson MP, Cohan C, Connor J (1988) Calcium regulation of the neuronal growth cone. Trends Neurosci 11:315-321.

Katz MJ (1985) Axon branch shapes. Brain Res 361:70-76.

Klämbt C, Jacobs JR, Goodman CS (1991) The midline of the Drosophila central nervous system: a model for the genetic analysis of cell fate, cell migration, and growth cone guidance. Cell 64:801-815.

Kuwada JY, Bernhardt RR, Chitnis AB (1990) Pathfinding by identified growth cones in the spinal cord of zebrafish embryos. J Neurosci 10:1299-1308.

Lefcourt F, Bentley D (1989) Organization of cytoskeletal elements and organelles preceding growth cone emergence from an identified neuron in situ. J Cell Biol 108:1737-1749.

Letourneau PC (1975) Cell-to-substratum adhesion and guidance of axonal elongation. Dev Biol 44:92-101.

Letourneau PC (1982) Nerve fibre growth and its regulation by extrinsic factors. In: Neuronal development (NC Spitzer, ed), pp 213254. New York: Plenum.

Levi-Montalcini R, Angeletti PU (1968) Nerve growth factor. Physiol Rev 48:534-569.

Lo Presti V, Macagno ER, Levinthal C (1974) Structure and development of neuronal connections in isogenic organisms: transient gap junctions between growing optic neurons and lamina neuroblasts. Proc Natl Acad Sci USA 71:1098-1102.

Myers PZ, Bastiani MJ (1992) Growth cone dynamics during the migration of an identified commissural growth cone. J Neurosci 13: 127-143.

Myers PZ, Eisen JS, Westerfield M (1986) Development and axonal outgrowth of identified motoneurons in the zebrafish. J Neurosci 6 : 2278-2289.

Placzek M, Tessier-Lavigne M, Jessel TM, Dodd J (1988) Tissue specificity and properties of a floor plate-derived factor that influences commissural axon outgrowth. Soc Neurosci Abstr 14:595.

Raper JA, Goodman CS (1981) Transient dye coupling between developing neurons reveals patterns of intracellular communication during embryogenesis. Paper presented at the sixth symposium on ocular visual development, held June 1981 in Philadelphia, PA.

Raper JA, Kapfhammer JP (1990) The enrichment of a neuronal growth cone collapsing activity from embryonic chick brain. Neuron $2: 21-29$.

Raper JA, Bastiani MJ, Goodman CS (1983) Pathfinding by neuronal growth cones in grasshopper embryos. I. Divergent choices made by the growth cones of sibling neurons. J Neurosci 3:20-30.

Sandell JH, Masland RH (1988) Photoconversion of some fluorescent markers to a diaminobenzidine product. J Histochem Cytochem 36: 555-559.

Taghert PH, Bastiani MJ, Ho RK, Goodman CS (1982) Guidance of pioneer growth cones: filopodial contacts and coupling revealed with an antibody to Lucifer yellow. Dev Biol 94:391-399.

Tessier-Lavigne M, Placzek M, Lumsden AGS, Dodd J, Jessel TM (1988) Chemotropic guidance of developing axons in the mammalian central nervous system. Nature 336:775-778.

Thoenen H, Bandtlow C, Heumann R (1987) The physiological function of nerve growth factor in the central nervous system: comparison with the periphery. Rev Physiol Biochem Pharmacol 109:145-178.

Tosney KW, Landmesser LT (1985) Growth cone morphology and trajectory in the lumbosacral region of the chick embryo. J Neurosci 5:2345-2358. 